\title{
RE-ENGINEERING AND DEVELOPMENT OF DRIED CASSAVA
}

\section{LEAVES PROCESSING}

\section{DOMINIQUE SAVIO NKUNDA}

Department of Biotechnology, INES Ruhengeri-Institute of Applied Sciences, Rwanda

\section{ABSTRACT}

The objective of this study was to minimize the energy used during cassava leaves processing and to assess acceptability of new product developed by addition of cow foot in the recipe.

Cassava leaves were processed in two methods. In the traditional method they were ground, cooked for 3-5 hours and dried into powder. In the re-engineered method they were only blanched and dried into powder. A triangle test conducted on the 2 powders with a panel of 21 members showed that panelists failed significantly (p>0.05) to distinguish them. The Qualitative Descriptive Analysis on both samples showed that the re-engineered powder presented higher values of priority criteria previously defined by the panelists: odor, cow foot odor, green color, and dark green colour.

The traditional and the re-engineered powders were cooked into soups. A third sample was prepared by cooking the traditional powder with cow feet. The panelists' preference increased in the following order: traditional soup < reengineered soup < cow foot flavored -traditional soup.

These findings are, for processors, an opportunity of cassava leaves process re-engineering and new product development.

KEYWORDS: Analytical Hierarchy Process, Cassava Leaves, Cow Foot, Quantitative Descriptive Analysis, ReEngineering \& Triangle Test

Received: Jun 25, 2018; Accepted: Jul 15, 2018; Published: Oct 01, 2018; Paper Id.: IJBTROCT20183

\section{INTRODUCTION}

The cassava is popular in tropical countries and particularly in sub-Saharan Africa. Both sweet (Manihot dulcis) and bitter varieties (Manihot utilissima) produce tubers and foliage used as food. The wild variety (Manihot glaziovii) does not yield tubers, but its foliage is appreciated as a leafy vegetable. The use of cassava leaves is widespread in West, Central and East Africa, where each country has its own recipe and process (Achidi et al, 2005).

The nutritional importance of cassava leaves was discovered very soon. Though the chemical composition is dependent on geographic location (Wobeto et al, 2006) they are a source of proteins, fiber, Ca, $\mathrm{Zn}, \mathrm{Ni}$ and $\mathrm{K}$ ( Fasuyi, 2005). The dry matter of cassava leaves contains $20-30 \%$ crude protein and the essential amino acids proportion is close to that of soybeans (Atchara et al, 2007). This makes cassava leaves an abundant source of food for humans and animal feed (Atchara et al, 2007; Bokanga, 1995; Latif and Muller, 2015; Oresegun et al, 2016; Umuhozariho et al, 2011).

However, the presence of antinutrients and toxic cyanogenic gluco sides are the major drawbacks in cassava leaves, which limit their human consumption. The cyanide content of cassava leaves is higher than in 
cassava root (Eggum, 1970; Guira et al, 2016; Oresegun et al, 2016). The content can be reduced by sun drying, oven drying, steaming and steeping, or their combination (Fasuyi, 2005).

The wild variety is the most preferred in Rwanda as a leafy vegetable. The home preparation method includes selecting and harvesting tender leaves, pounding, cooking in water with spices, adding oil and salt (Umuhozariho et al, 2011). This preparation technique is common in the Great Lakes Region, including the Democratic Republic of Congo, Uganda, Tanzania, Burundi and Rwanda. Usually the recipe is flavoured by adding cow feet de-haired by burning in a fire flame and scraping with a knife.

A few companies have adapted the above cassava leaves home preparation to a semi industrial level without addition of cow feet. Cassava leaves are harvested, transported to the processing facilities, trimmed, ground, cooked with spices in kettles, dried and packaged in paper bags. The final product is sold locally and exported to Europe and USA where it is well appreciated by African communities because of its extended self-life.

Processors are facing challenges due to the use of a large quantity of firewood with direct impact onthe environment. Some customers' feedbacks request the popular cow foot flavour in the recipe. The objective of this research was to address the double request of cassava leaves 'processors: re-engineering the process to reduce the quantity of firewood used, and assessing the acceptability of the new product developed with cow foot in the recipe.

\section{MATERIALS AND METHOD}

\subsection{Materials}

Raw materials including fresh cassava leaves, onion, leak, sweet pepper, rock salt, spinaches, garlic and cow's foot were purchased from a local Kigali market and were stored at room temperature in the laboratory of Food Processing of the College of Science and Technology of Kigali for 24h.

\subsection{Methods}

\subsubsection{Cassava Leaves Cooking}

Two different methods were used for cassava leaf powder processing. In the first, the traditional method, fresh cassava leaves, sweet pepper, leak and spinach were trimmed, washed with tap water, ground with a blender and cooked with rock salt at $98^{\circ} \mathrm{C}$ in an aluminium pan for 3 hours. The cooked mixture was then dried with an electric air dryer at $65^{\circ} \mathrm{C}$ for 14 to 15 hours and packaged in biodegradable plastic bags.

In the second, the re-engineered method, whole cassava leaves were trimmed, and blanched for $5 \mathrm{~min}$ in boiling water at $98^{\circ} \mathrm{C}$, drained, dried with the same electric air dryer as above and packaged in biodegradable plastic bags.

Both traditional cassava leaves powder and re-engineered cassava leaf powder was subjected to sensory analysis and Quantitative Descriptive Analysis (QDA) as shown in the paragraph 2.2.3.

A new product was prepared as follows: cow feet, beforehand de-haired by the use of fire, flame followed byknife scrapping, were steamed, de-boned with a stainless steel knife, cut into small pieces (around $2 \mathrm{~cm}$ ), cooked with the same ingredients used in the traditional method, dried and packaged. 


\subsubsection{Sensory Evaluation}

\subsubsection{Focus Group}

Raw traditional and re-engineered cassava leaves, powders, cooked traditional cassava leaves powder alone and cow foot flavoured were presented to a focus group of 21 members. The members were asked to choose objective words to describe them. The samples were analyzed using all senses except the taste for raw samples. A primary list of words for each sample was produced.

The list produced was reduced by using one single word for those with the same meaning, and discarding, after discussion, those which were found reasonably not appropriate to describe the samples. A secondary list was found by grouping the parameters describing the same criteria. Finally, each parameter was broken down into relevant sub criteria.

\subsubsection{Analytical Hierarchy Process (AHP)}

The main quality criteria and the corresponding sub criteria, produced by the focus group were subjected to the Analytic Hierarchy Process (AHP) following the methodology already used for potatoes (Nkunda and Niyonzima, 2015) to determine the weights of consumers' preference.

\subsubsection{Triangle Test}

The triangle test followed the methodology described by Ennis and reported by O'Sullivan (2012). It involved three coded samples simultaneously, two of which were identical. Each assessor was given one set of three coded samples and was asked to select the odd sample. Samples were presented an equal number of times in each of the two sets of three distinct permutations of order: $\mathrm{BAA}, \mathrm{AAB}, \mathrm{ABA}$ and $\mathrm{ABB}, \mathrm{BBA}, \mathrm{BAB}$. Assessors were asked specific relevant question(s) referring to the difference and their confidence in their answers. "No-difference" replies were allowed. Four difference tests were performed: Traditional powder versus re-engineered powder, Traditional soup versus re-engineered soup, re-engineered soup versus traditional soup flavoured by cow foot, traditional soup versus traditional soup flavoured by cow foot. For no-difference replies, they were allocated randomly to each of the categories of replies.

The difference tests followed the following protocols:

- Cooked samples when the panelists were not blindfolded (appearance, odour, taste and texture).

- $\quad$ Raw samples when the panelists were not blindfolded (appearance).

The panelists were asked to identify the odd sample out of the three presented in a random order.

\subsubsection{Quantitative Descriptive Analysis (QDA)}

The QDA was conducted on traditional cassava leaves powder, re-engineered cassava leaves powder, cooked traditional cassava leaves soup, cooked, re-engineered cassava leaves soup, and cooked traditional cassava leaves soup flavoured by cow foot. The samples were scored by a semi-trained sensory panel composed of 21 members. Panelists were given a card score with NOT on the left and VERY on the right, joined by a line showing the increasing intensity from NOT to VERY. To score each sub criterion previously defined by the focus group, with a pencil, the panelist showed the relative intensity of the criterion on the line joining NOT to VERY. The intensity was then measured in millimeters with a ruler and the mean of the 21 panelists was recorded. 


\subsubsection{Data Analysis}

Data were analysed by using MS Excel descriptive statistics.

\section{RESULTS AND DISCUSSIONS}

The 21 panelists found the words shown in the Table 1 to describe raw and cooked cassava leaves. The primary list led to the secondary list of criteria which were broken down into sub criteria. The definition of each criterion was agreed upon by consensus and is shown in the same Table 1.

Table 1: Words Found to Describe Raw and Cooked Cassava Leaves

\begin{tabular}{|c|c|c|c|}
\hline Primary List & Secondary List & Sub Criteria & Definition \\
\hline \multirow{20}{*}{$\begin{array}{ll}\text { - } & \text { Fineness } \\
\text { - } & \text { Spices } \\
\text { - } & \text { Odor } \\
\text { - } & \text { Color } \\
\text { - } & \text { Viscosity } \\
\text { - } & \text { Shelf life } \\
\text { - } & \text { Bones } \\
\text { - } & \text { Water holding } \\
\text { - } & \text { Nopacity fully cooked } \\
\text { - } & \text { Appropriate variety } \\
\text { - } & \text { Nutrients } \\
\text { - } & \text { Taste } \\
\text { - } & \text { ready to eat } \\
\text { - } & \text { Freshness } \\
\text { - } & \text { Not sour }\end{array}$} & \multirow{3}{*}{ Fineness } & Fine & Finely ground \\
\hline & & coarse & Coarsely ground \\
\hline & & Not ground & $\begin{array}{l}\text { Not ground or with large pieces of cassava } \\
\text { leaves }\end{array}$ \\
\hline & \multirow{3}{*}{ Thickness } & Firmness & The soup is firm \\
\hline & & Softness & Flows easily \\
\hline & & Stickiness & Sticks to fingers \\
\hline & \multirow{4}{*}{ Odour } & Natural odour & Natural odour of cassava leaves \\
\hline & & Spice odour & Odour of garlic, green pepper, leak, celery \\
\hline & & Odour cow foot & Odour of burned cow foot \\
\hline & & odour bone & Odour of bone marrow \\
\hline & \multirow{4}{*}{ Taste } & sourness & Cassava leaves have a sour taste \\
\hline & & saltiness & Salty taste \\
\hline & & burning taste & The cassava leaves have a burning taste \\
\hline & & sweetness & sweet taste \\
\hline & \multirow{3}{*}{ Colour } & green & green colour \\
\hline & & dark green & dark green colour \\
\hline & & Green yellow & Green yellow colour \\
\hline & \multirow{3}{*}{ Level of doneness } & Well done & $\begin{array}{l}\text { Situation of cassava leaves high tenderness } \\
\text { due to prolonged cooking }\end{array}$ \\
\hline & & Just done & $\begin{array}{l}\text { Situation of cassava leaves of fair } \\
\text { tenderness due insufficient cooking }\end{array}$ \\
\hline & & Not done & $\begin{array}{l}\text { Situation of cassava leaves of lack of } \\
\text { tenderness due to very poor cooking }\end{array}$ \\
\hline
\end{tabular}

The results of the pair wise comparison of the 6 quality attributes for cassava leaves through the AHP are shown in table 2 .

Table 2: Consolidated Matrix of Pair Wise Comparison of Quality Attributes of Cassava Leaves (AHP)

\begin{tabular}{|l|c|c|c|c|c|c|c|}
\hline & & Fineness & Thickness & Odour & Taste & Colour & Doneness \\
\hline & & $\mathbf{1}$ & $\mathbf{2}$ & $\mathbf{3}$ & $\mathbf{4}$ & $\mathbf{5}$ & $\mathbf{6}$ \\
\hline Fineness & 1 & $\mathbf{1}$ & 1 & $1 / 4$ & $1 / 4$ & $5 / 9$ & $1 / 4$ \\
\hline Thickness & 2 & $11 / 9$ & $\mathbf{1}$ & $1 / 5$ & $1 / 5$ & $5 / 6$ & $2 / 7$ \\
\hline Odor & 3 & $37 / 8$ & $43 / 4$ & $\mathbf{1}$ & $7 / 9$ & $32 / 5$ & 1 \\
\hline Taste & 4 & $35 / 7$ & 5 & $12 / 7$ & $\mathbf{1}$ & $24 / 5$ & $17 / 8$ \\
\hline Color & 5 & $17 / 9$ & $11 / 5$ & $2 / 7$ & $1 / 3$ & $\mathbf{1}$ & $3 / 7$ \\
\hline Doneness & 6 & $41 / 5$ & $32 / 5$ & $32 / 5$ & $1 / 2$ & $21 / 3$ & $\mathbf{1}$ \\
\hline
\end{tabular}

The normalized principal Eigenvector gave the weights or priorities of the quality attributes as shown in the Table 3. The weights had a large consensus of the four assessing groups (72.9\%) and the Consistency Ratio (CR) was $1.2 \%$. A 
CR higher than $10 \%$ is usually unacceptable because it reflects a high rate of transitivity contradictions. The priorities found were an important guidance for cassava leaves product development and relative resources allocation.

Table 3: Weights of Quality Attributes for Cassava Leaves as Assessed by Panelists through the AHP

\begin{tabular}{|l|l|c|c|}
\hline \multicolumn{1}{|c|}{ Criteria } & \multicolumn{1}{c|}{ Definition } & Weights & Rank \\
\hline Fineness & Level at which the leaves are ground & $6.10 \%$ & 6 \\
\hline Thickness & Level of firmness of the cooked soup of cassava leaves & $6.40 \%$ & 5 \\
\hline Odour & How the cassava leaves are smelling & $25.50 \%$ & 2 \\
\hline Taste & How the leaves are tasting when swallowed & $30.60 \%$ & 1 \\
\hline Colour & The colour of cassava leaves & $9.20 \%$ & 4 \\
\hline Doneness & Level of tenderness due to cooking & $22.30 \%$ & 3 \\
\hline
\end{tabular}

In the triangle test, visually the panelists failed significantly ( $\mathrm{p}>0.05$ ) to distinguish from each other the traditional and the re-engineered cassava leaves powders and therefore no significant preference was observed. Nor did they recognize significantly $(\mathrm{p}>0.05)$ the two from each other and from the cow foot flavored traditional flavor when cooked into soups. This means that processors can skip the steps of grinding and cooking of the traditional processing, saving the related investment, reducing the firewood with a positive impact on forestry conservation, and increasing the productivity through reduction of processing time. The 3-5 hours cooking step is replaced by 5-10 min of blanching. The re-engineered process does not change anything on the product perception by the consumers.

The results of the QDA of the traditional cassava leaf powder and the re-engineered cassava leaf powder are presented in Figure 1.

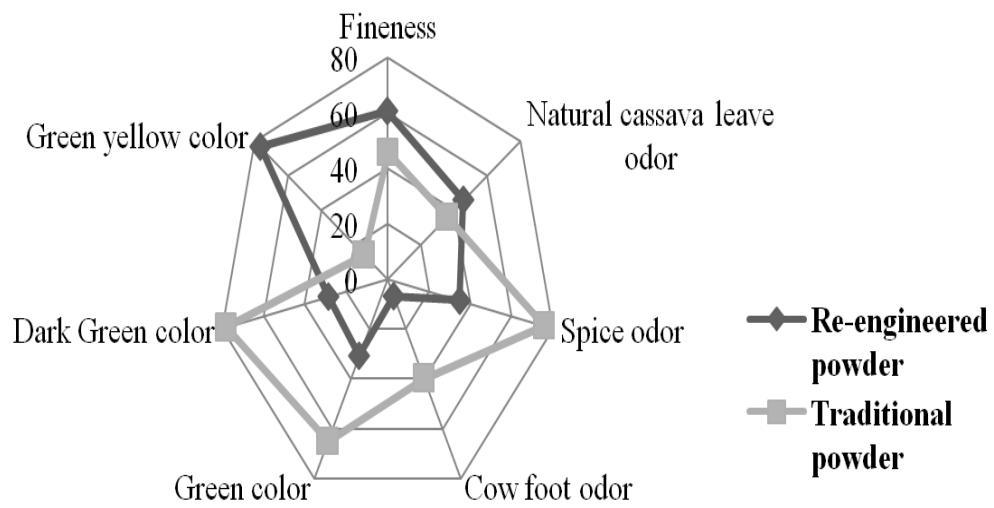

Figure 1: QDA Results for Traditional and Re-Engineered Cassava Leaves' Powders

They display some inconsistency reflected by large standard deviation values. This low consensus is to be imputed to the training level of panelists and insufficient accuracy of criteria definitions. However the priority criteria defined by the focus group have higher values in the re-engineered powder than in the traditional powder. That is the case for spice odour, cow foot odour, green colour, and dark green colour.

The same remarks were observed for the three cooked soups as shown in Figure 2. 


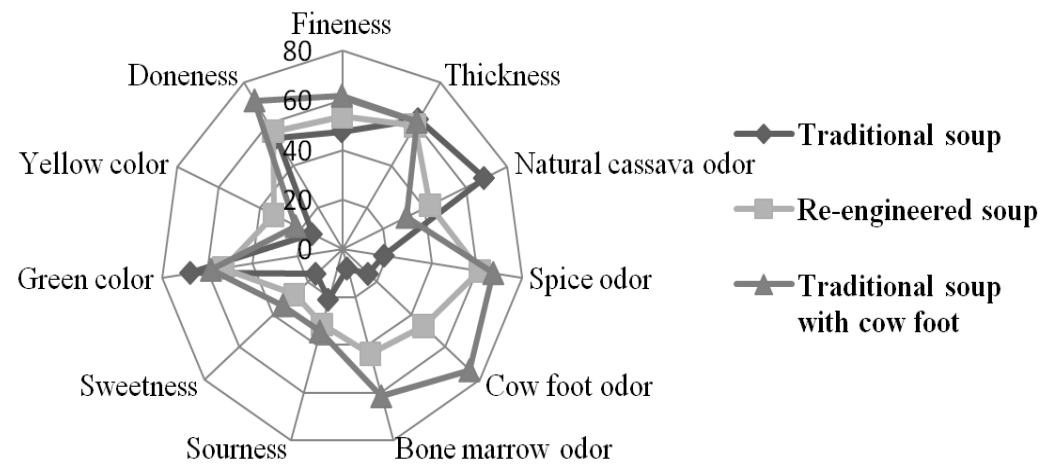

\section{Figure 2: QDA Results for Traditional Soup, Re-engineered Soup and Traditional Soup Flavoured by Cow Feet}

Like the cassava leaf powders the cooked soups attributes had large levels of dispersion for the same reasons invoked above. The panelists' preference increased in the following order: traditional soup < re-engineered soup < cow foot-traditional flavoured soup. This was obvious for fineness, thickness, spice odor, cow foot odor, bone marrow odor, sourness, sweetness, and doneness. These are then, for processors, opportunities of process re-engineering and new product development.

\section{CONCLUSIONS}

The cassava leaves process can be re-engineered to save energy used for grinding and firewood used for the long cooking. In this re-engineered process cassava leaves are not ground, but simply blanched and dried. The cooking step is done by the end user who usually cooks with a clean energy which does not harm the forest integrity. The re-engineered process was proven to keep the sensory perception of the final product.

The potential of cow foot flavouring give opportunities for new product development of industrialization of the home preparation. Indeed the flavored product has displayed higher values of the priority criteria defined by panelists.

\section{REFERENCES}

1. Aduni, A.; Olufunmide, A. ;Mpoko, B. ; Bosie, M. B. (2005). The Use of Cassava Leaves as Food in Africa. Ecology of Food and Nutrition 44(6):423-435 DOI10.1080/03670240500348771.

2. Atchara, L.; Saowaree, T.; Peaingpen, S.; Watana, W. (2007). Cassava leaf production research in Thailand. CIAT International Center for Tropical Agriculture.

3. Bokanga, M. (1995). Cassava: Opportunities for the food, feed, and other industries in Africa. Editions ORSTOM 558-569.

4. Eggun, B. O. (1970). The protein quality of cassava leaves. Br. J. Nutr. (1970), 24, 761.

5. Fasuyi, A. O. (2005). Nutrient Composition and Processing Effects on Cassava Leaf (Manihot esculenta, Crantz) Antinutrients. Pakistan J of Nutr 4 (1): 37-42, 2005. ISSN 1680-5194.

6. Guira Flibert, Tankoano Abel and Savadogo Aly. (2016). African cassava Traditional Fermented Food: The Microorganism's Contribution to their Nutritional and Safety Values-A Review. Int. J. Curr. Microbiol. App. Sci. 5(10): 664-687. Retrieved from: http://dx.doi.org/10.20546/ijcmas.2016.510.074. 
7. Latif, S.; Muller, J. (2015). Potential of cassava leaves in human nutrition: A review. Trends in Food Science \& Technology 44(2) DOI 10.1016/j.tifs.2015.04.006.

8. UKPE, E., \& Mustapha, S. D. S. (2016). Agricultural knowledge management: A case study of Nigeria cassava production process. J. Agric. Sci. Res, 3, 11-16.

9. Nkunda, D. S.; Niyonzima, E. (2016). Fresh Potato Requirements as Perceived by Consumers in Kigali City (Rwanda): An Investigation through the Analytical Hierarchy Process. Intl J of Agric Sci and Res (IJASR) ISSN(P): 2250-0057; ISSN(E): 2321-0087 Vol. 6, (3): 109-116.

10. Oresegun, A; Fagbenro, O. A.; Ilona, P.; Bernard, E. (2016). Nutritional and anti-nutritional composition of cassava leaf protein concentrate from six cassava varieties for use in aqua feed. Cogent Food \& Agriculture (2016), 2: 1147323.

11. O'Sullivan, M. G. (2017). New Product Development. Innovative Technologies for Food and Beverage Industry. A Handbook for Sensory-Driven New Product Development. Elsevier Science. ISBN:978-0-08-100357.

12. Umuhozariho, M. G.; Shayo, N. B.; Msuya, J. M. and Sallah, P. Y. K. (2011). Utilization of Cassava Leaves as a Vegetable in Rwanda Rwanda Journal ISSN 2305-2678 (Print); ISSN 2305-5944).

13. Wobeto, C.; Corrêa, A. D.; Abreu, A. M. P.; Santos, C. D.; Abreu, J. R. (2006). Nutrients in the Cassava (Manihot esculenta Crantz) Leaf Meal at three Ages of the Plant. Ciênc. Tecnol. Aliment. Campinas, 26(4): 865-869. 
